\title{
British Journal of Sports Medicine
}

\section{Promoting physical activity for mental health in a refugee camp: the Skaramagas project}

\begin{tabular}{|c|c|}
\hline Journal: & British Journal of Sports Medicine \\
\hline Manuscript ID & bjsports-2021-104636.R4 \\
\hline Article Type: & Service spotlight \\
\hline $\begin{array}{r}\text { Date Submitted by the } \\
\text { Author: }\end{array}$ & $n / a$ \\
\hline Complete List of Authors: & Adamakis, Manolis; University College Cork \\
\hline Keywords: & Adolescent, Education, Exercise, Health promotion, Physical activity \\
\hline
\end{tabular}

\section{SCHOLARONE \\ Manuscripts}


I, the Submitting Author has the right to grant and does grant on behalf of all authors of the Work (as defined in the below author licence), an exclusive licence and/or a non-exclusive licence for contributions from authors who are: i) UK Crown employees; ii) where BMJ has agreed a CC-BY licence shall apply, and/or iii) in accordance with the terms applicable for US Federal Government officers or employees acting as part of their official duties; on a worldwide, perpetual, irrevocable, royalty-free basis to BMJ Publishing Group Ltd ("BMJ") its licensees and where the relevant Journal is co-owned by BMJ to the co-owners of the Journal, to publish the Work in this journal and any other BMJ products and to exploit all rights, as set out in our licence.

The Submitting Author accepts and understands that any supply made under these terms is made by BMJ to the Submitting Author unless you are acting as an employee on behalf of your employer or a postgraduate student of an affiliated institution which is paying any applicable article publishing charge ("APC") for Open Access articles. Where the Submitting Author wishes to make the Work available on an Open Access basis (and intends to pay the relevant APC), the terms of reuse of such Open Access shall be governed by a Creative Commons licence - details of these licences and which Creative Commons licence will apply to this Work are set out in our licence referred to above.

Other than as permitted in any relevant BMJ Author's Self Archiving Policies, I confirm this Work has not been accepted for publication elsewhere, is not being considered for publication elsewhere and does not duplicate material already published. I confirm all authors consent to publication of this Work and authorise the granting of this licence. 
1 Promoting physical activity for mental health in a refugee camp: the Skaramagas project

2 Author: Manolis Adamakis ${ }^{1,2}$

3 1. Affiliation: School of Education, University College Cork, Ireland

4 Address: Leeholme, O' Donovan's Road, Cork, Ireland

5 2. Affiliation: Department of Education and Social Work, University of Luxembourg, $6 \quad$ Luxembourg

7 Address: Belval Campus, Esch-sur-Alzette, Luxembourg

8 Email: manosadam@phed.uoa.gr

9

10

Background

11

12

Many refugee and migrant children and adolescents are in urgent need of shelter, care, and protection. Greece has been a major entry point in Europe, receiving over a million refugees and migrants (37\% children) since the beginning of 2015 . These children and their families face a range of risks, such as violence, exploitation, and abuse in their country of origin, during their journey, and upon arrival. It is estimated that $22 \%$ of individuals living in displacement experience a mental disorder such as depression, anxiety, posttraumatic stress disorder, bipolar disorder, or schizophrenia. ${ }^{1}$ Promising examples of community-based initiatives, which use culturally sensitive learning materials, ${ }^{2}$ to encourage participation in physical activity for the purpose of promoting mental health are emerging. ${ }^{3,4}$ This Service Spotlight focuses on one such initiative: the Skaramagas project.

\section{The Skaramagas project}

Skaramagas is an old navy base located $11 \mathrm{~km}$ west of Athens. During the summer of 2016, Skaramagas accommodated 3,000 refugees, of whom 96\% were families from Syria, Iraq, and Afghanistan. From November 2016 to May 2018, an educational programme sponsored by UNICEF and the British Council of Greece was created for refugee and migrant adolescents living in the camp by providing access to and/or facilitating their education, school readiness, psychosocial support, and the development of resilience. Educators planned a series of lessons based on common themes, such as safety, goals and inspirations, self-care and hygiene measures, Olympic games, and physical activity.

In total, 269 adolescents (50\% girls) aged 12 to 17 years old participated, with an average weekly attendance of 125 students. Students originated from Syria (47\%), Iraq (39\%), Afghanistan (13\%) and Iran (1\%). The students' native languages included Kurdish (53\%), 
34 Arabic (34\%) and Dari/Farsi (13\%). On average, the participants in the programme had missed

\section{5 years of schooling, while some had never attended formal education at all.}

\section{Purpose of the physical activity programme}

The physical activity programme, which was part of the Skaramagas project, was developed to promote physical and mental health of adolescent refugees and migrants through structured sport, physical activity, and play. The main aims were to offer suitable participation opportunities for adolescents, increase the physical activity level of the participants, as well as introduce them to unfamiliar sports, and the respective new sport skills. In addition, the programme intended to create a supportive and inclusive environment within a culturally sensitive approach. Further objectives were the promotion of mental health and psychosocial wellbeing through physical activity and sport participation, with minimum emphasis on performance and competition. Prior to the programme's implementation, participants had limited or no opportunities to be physically active and had not participated in structured physical activity sessions for many years.

The programme consisted primarily of football, basketball, volleyball, and a combination of endurance and weight training. Calisthenics, and weight training using sand-filled bottles, big water bottles, and body weight were key, especially for older students. The physical education teacher determined the session's activities with no specifications regarding the intensity of activities. The programme was delivered three times per week with each exercise session lasting 50 minutes, and participants were free to choose the intensity they preferred.

\section{Challenges faced and lessons learned}

The initial plan was to implement the Sport Education model because it is a student-centred educational approach that contains cooperative learning, meaningful game experiences, and various role tasks for students, and has a positive impact on adolescents' physical and psychological variables. ${ }^{5}$ However, this approach was abandoned early because the tension and emotional involvement attached to competitions obscured the attainment of social goals and values, and countered the psychosocial support and resilience development goals of the programme. Thus, the Sport Education model was replaced by the Teaching Personal and Social Responsibility (TPSR) through Physical Activity model. ${ }^{6}$ The TPSR model promotes self-direction, empathy, respect for others' rights, cooperation, and leadership skills by giving students increased amounts of responsibility and decision-making. A student-centred 

95

methodology through skill building and increased physical activity has fostered independence and improved decision-making skills for students.

Another challenge was developing mixed-cultural and mixed-gender groups. This was important to facilitate inclusion and prepare students for formal schooling. The ethnic and cultural tensions of the various communities' historical background were overcome by openminded students who embraced multi-cultural/multi-gender small-group exercising experiences.

\section{The impact of the programme on the community}

A climate of acceptance, diversity and gender equality was created through positive engagement in physical activity, and participants reported improvement of their mental health and psychosocial wellbeing. Older students exercised without direct supervision and took responsibility for their actions. The programme successfully fostered an active participatory role, promoting empowerment, self-confidence, and eagerness to take an initiative in physical activities. It also developed team-building and intercultural understanding, breaking gender barriers and fostering tolerance and social cohesion. Most of the girls had never played sports before and were reluctant to participate in mixed gender groups, so playing together was emphasized to include girls safely and appropriately. Over time, students self-organized mixedgender and nationality groups to play outdoor games and sports (e.g., volleyball) during breaks and afternoon recess.

\section{Sustainability and replicability elements of the programme}

This physical activity programme was based on the Sport for Protection Toolkit developed by UNHCR, the International Olympic Committee and Terre des Hommes. ${ }^{7}$ It was integrated in a holistic approach to facilitate refugee and migrant adolescent education, school readiness, psychosocial support, physical and mental health, and resilience. Delivered by a specialized physical educator with the assistance of a school psychologist, the programme established meaningful team sport participation opportunities for young women across nationalities.

\section{Conclusion}

The Skaramagas project showed that physical activity interventions appropriately implemented by adequately trained physical activity professionals can promote the physical and mental health of adolescent refugees and migrants. Sport and exercise professionals should bear in 
100 101 102

103

104

105

106

107

108

109

110

111

112

113

114

115

116

117

118

119

mind that refugees and migrants are not a homogeneous population, and, thus, physical activity programmes should be tailored to individual needs and constantly re-evaluated.

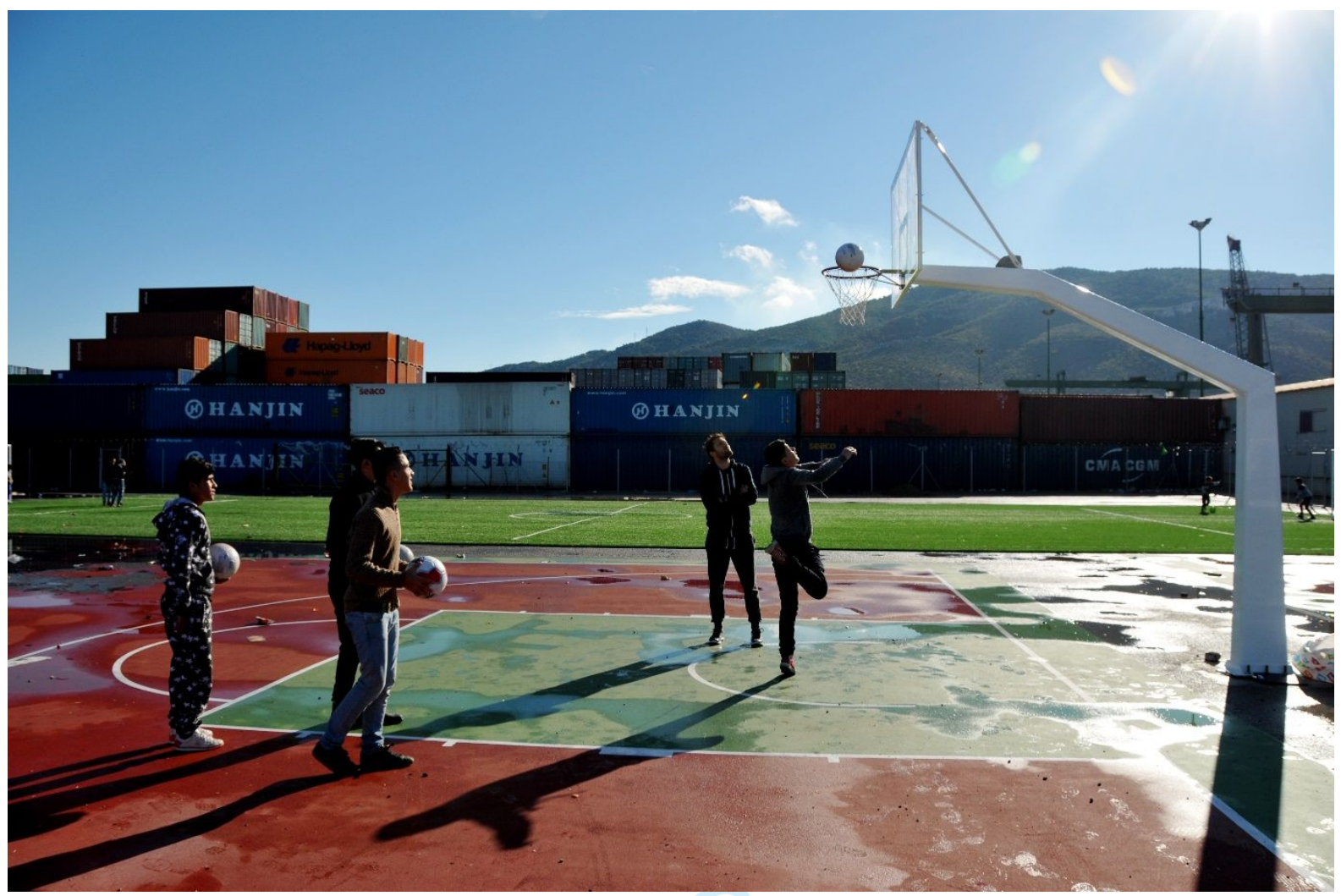

Figure 1 Participants in the physical activity programme supervised by the physical education teacher at Skaramagas refugee camp.

\section{References}

1. Charlson F, Ommeren MV, Flaxman A, et al. New WHO prevalence estimates of mental disorders in conflict settings: a systematic review and meta-analysis. Lancet 2019;394(10194):240-248. https://doi.org/10.1016/S0140-6736(19)30934-1

2. Rosenbaum S, Danielson S, Baggenstos B. Promoting physical activity for mental health in contexts of displacement. Br J Sport Med Blog May 2021. Available at: https://blogs.bmj.com/bjsm/2021/05/31/promoting-physical-activity-for-mental-health-incontexts-of-displacement/

3. Ley C, Barrio MR. Promoting health of refugees in and through sport and physical activity: A psychosocial, trauma-sensitive approach. In: Wenzel T, Drožđek B, eds. An Uncertain Safety. Springer, Cham. 2019:301-343. https://doi.org/10.1007/978-3-319-72914-5_13

4. Rosenbaum S, Ager A, Snider L, Warria A, Collison H, Hermosilla S, Vancampfort D. Physical activity, mental health and psychosocial support. Forced Migr Rev 2021;66:34-37. 
120 5. Siedentop D, Hastie P, van der Mars H. Complete guide to Sport Education (2 ${ }^{\text {nd }}$ ed). 121 Champain, IL: Human Kinetics 2011.

122 6. Hellison D. Teaching personal and social responsibility through physical activity ( $3^{\text {rd }}$ ed). 123 Champain, IL: Human Kinetics 2011.

124 7. UNHCR, International Olympic Committee, Terre des Hommes. Sport for protection toolkit:

125 Programming with young people in forced displacement settings. September 2021. 126 Available at: $\underline{\text { bit.ly/Sport-for-protection-toolkit-2018 }}$

127

128 Contributors: MA is the sole contributing author.

129 Funding: The authors have not declared a specific grant for this research from any funding 130 agency in the public, commercial or not-for-profit sectors.

131 Competing interests: None declared.

132 Patient consent for publication: Not required.

133 Data availability statement: No data are available. Not applicable. 
1 Promoting physical activity for mental health in a refugee camp: the Skaramagas project

2 Author: Manolis Adamakis ${ }^{1,2}$

3 1. Affiliation: School of Education, University College Cork, Ireland

4 Address: Leeholme, O' Donovan's Road, Cork, Ireland

5 2. Affiliation: Department of Education and Social Work, University of Luxembourg, $6 \quad$ Luxembourg

7 Address: Belval Campus, Esch-sur-Alzette, Luxembourg

$8 \quad$ Email: manosadam@phed.uoa.gr

9

10

\section{Background}

11

12

Many refugee and migrant children and adolescents are in urgent need of shelter, care, and protection. Greece has been a major entry point in Europe, receiving over a million refugees and migrants (37\% children) since the beginning of 2015 . These children and their families face a range of risks, such as violence, exploitation, and abuse in their country of origin, during their journey, and upon arrival. It is estimated that $22 \%$ of individuals living in displacement experience a mental disorder such as depression, anxiety, posttraumatic stress disorder, bipolar disorder, or schizophrenia. ${ }^{1}$ Promising examples of community-based initiatives, which use culturally sensitive learning materials, ${ }^{2}$ to encourage participation in physical activity for the purpose of promoting mental health are emerging. ${ }^{3,4}$ This Service Spotlight focuses on one such initiative: the Skaramagas project.

\section{The Skaramagas project}

Skaramagas is an old navy base located $11 \mathrm{~km}$ west of Athens. During the summer of 2016, Skaramagas accommodated 3,000 refugees, of whom 96\% were families from Syria, Iraq, and Afghanistan. From November 2016 to May 2018, an educational programme sponsored by UNICEF and the British Council of Greece was created for refugee and migrant adolescents living in the camp by providing access to and/or facilitating their education, school readiness, psychosocial support, and the development of resilience. Educators planned a series of lessons based on common themes, such as safety, goals and inspirations, self-care and hygiene measures, Olympic games, and physical activity.

In total, 269 adolescents (50\% girls) aged 12 to 17 years old participated, with an average weekly attendance of 125 students. Students originated from Syria (47\%), Iraq (39\%), Afghanistan (13\%) and Iran (1\%). The students' native languages included Kurdish (53\%), 
34 Arabic (34\%) and Dari/Farsi (13\%). On average, the participants in the programme had missed

2.5 years of schooling, while some had never attended formal education at all.

\section{Purpose of the physical activity programme}

The physical activity programme, which was part of the Skaramagas project, was developed to promote physical and mental health of adolescent refugees and migrants through structured sport, physical activity, and play. The main aims were to offer suitable participation opportunities for adolescents, increase the physical activity level of the participants, as well as introduce them to unfamiliar sports, and the respective new sport skills. In addition, the programme intended to create a supportive and inclusive environment within a culturally sensitive approach. Further objectives were the promotion of mental health and psychosocial wellbeing through physical activity and sport participation, with minimum emphasis on performance and competition. Prior to the programme's implementation, participants had limited or no opportunities to be physically active and had not participated in structured physical activity sessions for many years.

The programme consisted primarily of football, basketball, volleyball, and a combination of endurance and weight training. Calisthenics, and weight training using sand-filled bottles, big water bottles, and body weight were key, especially for older students. The physical education teacher determined the session's activities with no specifications regarding the intensity of activities. The programme was delivered three times per week with each exercise session lasting 50 minutes, and participants were free to choose the intensity they preferred.

\section{Challenges faced and lessons learned}

The initial plan was to implement the Sport Education model because it is a student-centred educational approach that contains cooperative learning, meaningful game experiences, and various role tasks for students, and has a positive impact on adolescents' physical and psychological variables. ${ }^{5}$ However, this approach was abandoned early because the tension and emotional involvement attached to competitions obscured the attainment of social goals and values, and countered the psychosocial support and resilience development goals of the programme. Thus, the Sport Education model was replaced by the Teaching Personal and Social Responsibility (TPSR) through Physical Activity model. ${ }^{6}$ The TPSR model promotes self-direction, empathy, respect for others' rights, cooperation, and leadership skills by giving students increased amounts of responsibility and decision-making. A student-centred 

95

methodology through skill building and increased physical activity has fostered independence and improved decision-making skills for students.

Another challenge was developing mixed-cultural and mixed-gender groups. This was important to facilitate inclusion and prepare students for formal schooling. The ethnic and cultural tensions of the various communities' historical background were overcome by openminded students who embraced multi-cultural/multi-gender small-group exercising experiences.

\section{The impact of the programme on the community}

A climate of acceptance, diversity and gender equality was created through positive engagement in physical activity, and participants reported improvement of their mental health and psychosocial wellbeing. Older students exercised without direct supervision and took responsibility for their actions. The programme successfully fostered an active participatory role, promoting empowerment, self-confidence, and eagerness to take an initiative in physical activities. It also developed team-building and intercultural understanding, breaking gender barriers and fostering tolerance and social cohesion. Most of the girls had never played sports before and were reluctant to participate in mixed gender groups, so playing together was emphasized to include girls safely and appropriately. Over time, students self-organized mixedgender and nationality groups to play outdoor games and sports (e.g., volleyball) during breaks and afternoon recess.

\section{Sustainability and replicability elements of the programme}

This physical activity programme was based on the Sport for Protection Toolkit developed by UNHCR, the International Olympic Committee and Terre des Hommes. ${ }^{7}$ It was integrated in a holistic approach to facilitate refugee and migrant adolescent education, school readiness, psychosocial support, physical and mental health, and resilience. Delivered by a specialized physical educator with the assistance of a school psychologist, the programme established meaningful team sport participation opportunities for young women across nationalities.

\section{Conclusion}

The Skaramagas project showed that physical activity interventions appropriately implemented by adequately trained physical activity professionals can promote the physical and mental health of adolescent refugees and migrants. Sport and exercise professionals should bear in 
100

101

102

103

104

105

106

107

108

109

110

111

112

113

114

115

116

117

118

119

mind that refugees and migrants are not a homogeneous population, and, thus, physical activity programmes should be tailored to individual needs and constantly re-evaluated.

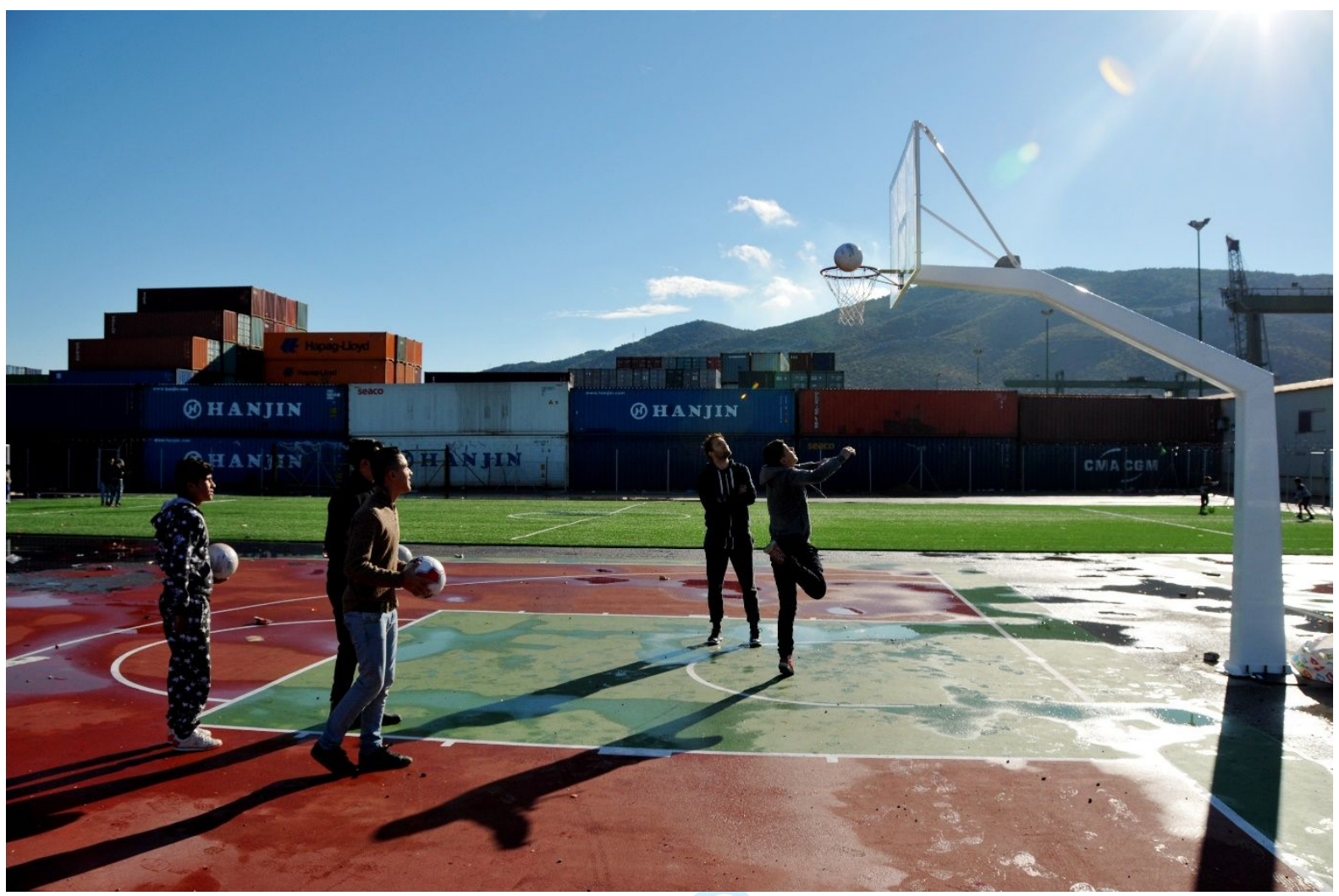

Figure 1 Participants in the physical activity programme supervised by the physical education teacher at Skaramagas refugee camp.

\section{References}

1. Charlson F, Ommeren MV, Flaxman A, et al. New WHO prevalence estimates of mental disorders in conflict settings: a systematic review and meta-analysis. Lancet 2019;394(10194):240-248. https://doi.org/10.1016/S0140-6736(19)30934-1

2. Rosenbaum S, Danielson S, Baggenstos B. Promoting physical activity for mental health in contexts of displacement. Br J Sport Med Blog May 2021. Available at: https://blogs.bmj.com/bjsm/2021/05/31/promoting-physical-activity-for-mental-health-incontexts-of-displacement/

3. Ley C, Barrio MR. Promoting health of refugees in and through sport and physical activity: A psychosocial, trauma-sensitive approach. In: Wenzel T, Drožđek B, eds. An Uncertain Safety. Springer, Cham. 2019:301-343. https://doi.org/10.1007/978-3-319-72914-5_13

4. Rosenbaum S, Ager A, Snider L, Warria A, Collison H, Hermosilla S, Vancampfort D. Physical activity, mental health and psychosocial support. Forced Migr Rev 2021;66:34-37. 
120 5. Siedentop D, Hastie P, van der Mars H. Complete guide to Sport Education (2 ${ }^{\text {nd }}$ ed). 121 Champain, IL: Human Kinetics 2011.

122 6. Hellison D. Teaching personal and social responsibility through physical activity ( $3^{\text {rd }}$ ed). 123 Champain, IL: Human Kinetics 2011.

124 7. UNHCR, International Olympic Committee, Terre des Hommes. Sport for protection toolkit: 125 Programming with young people in forced displacement settings. September 2021. 126 Available at: bit.ly/Sport-for-protection-toolkit-2018

127

128 Contributors: MA is the sole contributing author.

129 Funding: The authors have not declared a specific grant for this research from any funding 130 agency in the public, commercial or not-for-profit sectors.

131 Competing interests: None declared.

132 Patient consent for publication: Not required.

133 Data availability statement: No data are available. Not applicable. 


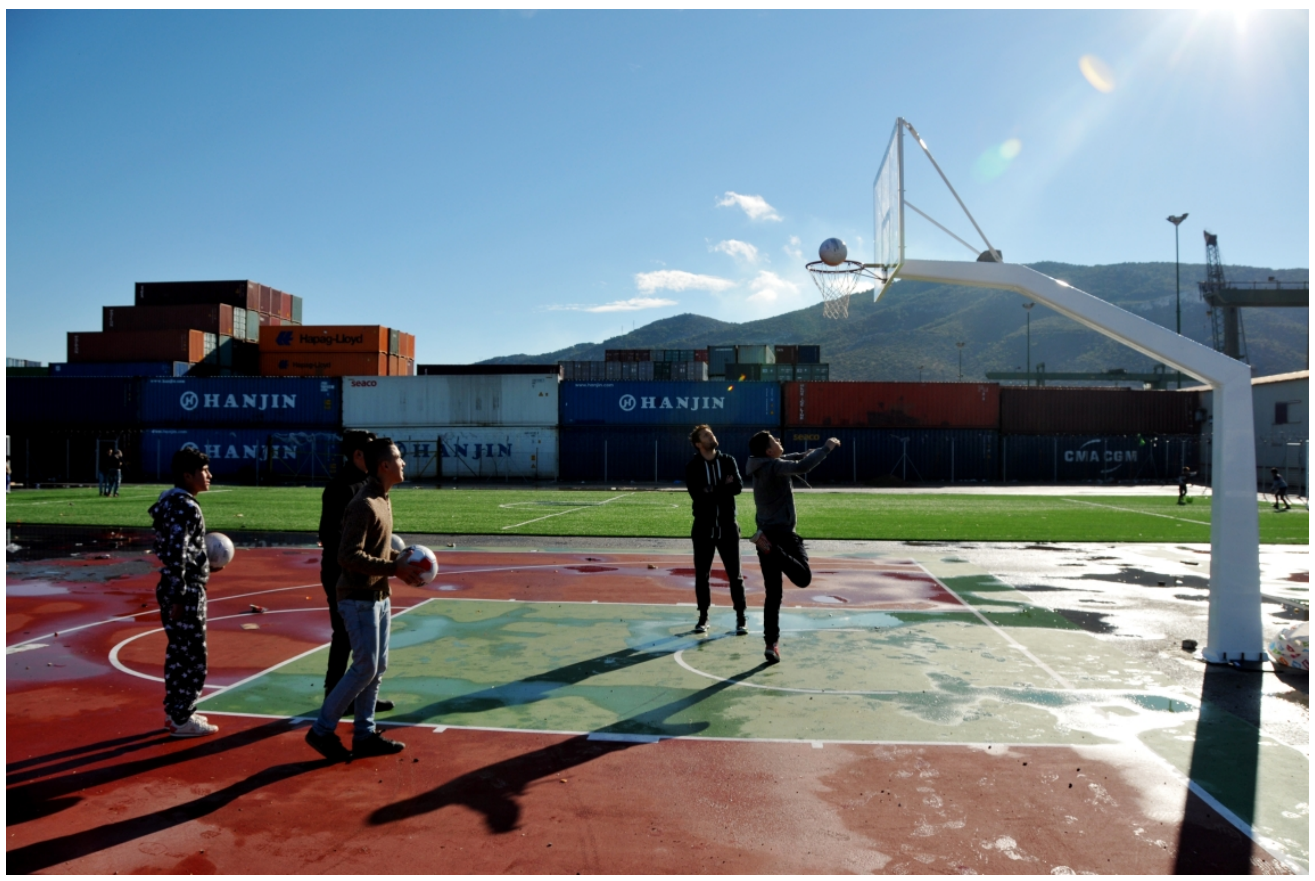

Figure 1 Participants in the physical activity programme supervised by the physical education teacher at Skaramagas refugee camp.

$363 \times 241 \mathrm{~mm}(300 \times 300 \mathrm{DPI})$ 